\title{
Precocious detection on amphibian oocyte lampbrush chromosomes of subtle changes in the cellular localisation of the Ro52 protein induced by in vitro culture
}

\author{
May Penrad-Mobayed • Caroline Perrin • \\ Jean-Antoine Lepesant
}

Published online: 14 November 2012

(C) Springer Science+Business Media Dordrecht 2012

\begin{abstract}
Subterminal lampbrush loops of one of the 12 bivalents of the oocyte karyotype of Pleurodeles waltl (Amphibian, Urodele) underwent prominent morphological changes upon in vitro culture. These loops exhibited a fine ribonucleoprotein (RNP) granular matrix, which evolved during culture into huge structures that we have named 'chaussons' (slippers). This phenomenon involved progressive accumulation of proteins in the RNP matrix without protein neosynthesis. One of these proteins, which translocated into the nucleus during the culture, was identified as a homolog of the human Ro52 E3 ubiquitin ligase. RNA polymerase III was also found to accumulate on the same loops. These results suggest that the subterminal loops of bivalent XII act as a storage site for the components of a nuclear machinery involved in the quality control of RNA synthesis and maturation in response to cellular stress. They also emphasise the considerable value of the lampbrush chromosome system for a direct visualisation of modifications in gene expression and open the
\end{abstract}

Responsible Editor: Herbert Macgregor

M. Penrad-Mobayed $(\bowtie) \cdot$ C. Perrin $\cdot$ J.-A. Lepesant Institute Jacques Monod, CNRS and University

Paris-Diderot,

15 rue Hélène Brion,

75205 Paris Cedex13, France

e-mail: penrad@ijm.univ-paris-diderot.fr question of a nuclear accumulation of Ro52 in human or animal oocytes cultured in vitro for assisted reproductive technologies (ART).

Keywords Amphibian Pleurodeles waltl - oocyte · lampbrush chromosomes $\cdot$ Ro52/TRIM21 $\cdot$ RNA pol III

$\begin{array}{ll}\text { Abbreviations } \\ \text { ART } & \text { Assisted reproductive technologies } \\ \text { BSA } & \begin{array}{l}\text { Bovine serum albumin } \\ \text { DAPI }\end{array} \\ & \begin{array}{l}\text { }^{-} \text {-Diamidino-2-phenylindole } \\ \text { dihydrochloride }\end{array} \\ \text { ECL } & \text { Enhance chemiluminescence } \\ \text { GV } & \text { Germinal vesicle } \\ \text { LBC } & \text { Lampbrush chromosome } \\ \text { LE } & \text { Left extremity } \\ \text { MBS } & \text { Modified Barth's solution } \\ \text { MS222 } & \text { Tricaine methane sulfonate } \\ \text { NO } & \text { Nitric oxide } \\ \text { PBS } & \text { Phosphate-buffered saline } \\ \text { PBST } & \text { Phosphate-buffered saline }+ \text { Tween } \\ \text { Pol III } & \text { RNA polymerase III } \\ \text { PVDF } & \text { Polyvinylidenedifluoride } \\ \text { RING } & \text { Really interesting new gene } \\ \text { RNP } & \text { Ribonucleoprotein } \\ \text { RE } & \text { Right extremity } \\ \text { SLE } & \text { Systemic lupus erythematosus } \\ \text { SLL } & \text { Left subterminal loops } \\ \text { SLR } & \text { Right subterminal loop } \\ \text { SS } & \text { Sjörgren's syndrome }\end{array}$


TCA Trichloroacetic acid

TRIM Tripartite motif

\section{Introduction}

Over the last five decades, the amphibian oocyte has been widely used as an experimental system to study complex biological processes. Because of its large size and easy manipulation, in vitro translated RNA, plasmid DNA, proteins or somatic nuclei can be easily injected into the cytoplasm or the large nucleus, also called germinal vesicle $(\mathrm{GV}$; for a review, see HalleyStott et al. 2010). The fate of these exogenous elements can be investigated by further in vitro culture of the injected oocyte, in which RNA transcription and protein synthesis may continue for up to several weeks.

The germinal vesicle contains lampbrush chromosomes (LBCs) which are giant in size and actively transcribed. They are considered as a prime model for the analysis of transcriptional and posttranscriptional processes (for a review, see Morgan 2002; Gall et al. 2004; Sommerville 2010; Macgregor 2012). At the diplotene stage, these chromosomes are associated in bivalents whose axes comprised a succession of highly condensed chromatin regions, the chromomeres, from which lateral loops unfold that are the sites of intense RNA synthesis. The nascent RNA transcripts associate with proteins to form the ribonucleoprotein (RNP) matrix of the loops, with some proteins common to all lateral loops and others specific of a subset. Almost all loops share a common basic organisation with transcripts appearing as fibrils comprising 30-nm RNP particles, but they differ in their size and the degree of aggregation of the RNP fibrils. Whilst the majority of the loops conform to a standard type in which the RNP matrix exhibits a fine fibrous texture, others such as the granular, globular and giant fusing loops display distinct morphologies. They are always observed at the same chromosomal loci and constitute obvious landmarks, which enabled LBC maps to be drawn up in many newt species (for a review, see Callan 1986) and in the anurans Xenopus laevis (Callan et al. 1987) and Xenopus tropicalis (Penrad-Mobayed et al. 2009). LBCs have also been used as a powerful system for a direct visualisation of changes in gene expression in the oocyte. Their architecture is dynamic and directly related to transcriptional and posttranscriptional processes any modifications of which are reflected by concomitant morphological variations in chromosomal structure. Thus, analysis of LBCs after cold or heat shock treatment revealed a morphological evolution of specific loops, which occurred at constant and reproducible loci (for a review, see Angelier et al. 1990).

We report here the observation of such a prominent morphological development affecting the subterminal loops of bivalent XII in full-grown (stage VI) oocytes (Bonnanfant-Jaïs and Mentré 1983) of the newt Pleurodeles waltl (Amphibian, Urodele) when cultured in vitro. Using polyclonal antibodies, we provide evidence that this major structural change was concomitant with an accumulation of the Ro52 E3 ubiquitin ligase and RNA polymerase III (pol III) on these loops.

\section{Materials and methods}

Oocyte culture

P. waltl were raised in our laboratory at $18{ }^{\circ} \mathrm{C}$. Ovarian biopsies were performed on adult females anaesthetized in $0.15 \%$ MS222 (Sigma Chemical, St. Louis, MO). Oocytes were defolliculated for $2-3 \mathrm{~h}$ in saline buffer OR2 containing $0.15 \%$ collagenase type I (Sigma Chemical). Full-grown oocytes (stage VI; BonnanfantJaïs and Mentré 1983) were selected and incubated at $18^{\circ} \mathrm{C}$ either in modified Barth's solution (MBS) buffer (Gurdon 1977) or in the 199 culture medium with $25 \mathrm{mmol} / \mathrm{L}$ HEPES (Gibco) supplemented with gentamycin $(5 \mu \mathrm{g} / \mathrm{mL})$. Oocytes were incubated with cycloheximide $(200 \mu \mathrm{g} / \mathrm{ml})$ for $24 \mathrm{~h}$, as indicated.

Nuclear spreads and immunofluorescence

Germinal vesicles from stage VI oocytes were manually isolated in $75 \mathrm{mmol} / \mathrm{L} \mathrm{KCl}, 25 \mathrm{mmol} / \mathrm{L} \mathrm{NaCl}, 1 \mathrm{mmol} / \mathrm{L}$ $\mathrm{MgCl}_{2}$ and $0.05 \mathrm{mmol} / \mathrm{L} \mathrm{CaCl} 2$ (pH 7.2); lampbrush chromosomes were prepared as described previously (Penrad-Mobayed et al. 2010). Nuclear spread preparations were fixed for $30 \mathrm{~min}$ at $4{ }^{\circ} \mathrm{C}$ in phosphate-buffered saline (PBS) containing $2 \%$ paraformaldehyde and $1 \mathrm{mM} / \mathrm{L} \mathrm{MgCl}_{2}$, washed with PBS and blocked for $10 \mathrm{~min}$ with horse serum at $10 \%$ dilution. They were then incubated with a rabbit polyclonal anti-Ro52 antiserum (Ricchiuti et al. 1997; kindly supplied by S. Muller, I.B.M.C, Strasbourg) at 1:250 dilution or a rabbit polyclonal anti-RPC53 (kindly supplied by R.G. Roeder, 
Rockefeller University) directed against a pol III subunit at a 1:250 dilution. After washing with PBS, preparations were incubated with the secondary antibody (Alexa 488 goat anti-rabbit IgG, Invitrogen Corp., or biotinylated goat anti-rabbit diluted 1:50 and Texas Red-streptavidin diluted 1:50). Preparations were post-stained either with 4',6-diamidino-2-phenylindole dihydrochloride (DAPI) at a concentration of $0.5 \mu \mathrm{g} / \mathrm{mL}$ or Hoechst 33342 (1:1,000). Fluorescence microscopy was performed using a Leitz DMRB CDD camera and the images assembled using Adobe Photoshop.

Incubation conditions for in vitro RNA synthesis and autoradiography

Oocytes were incubated in MBS buffer which contained $250 \mu \mathrm{Ci} / \mathrm{mL}$ of $5,6-3 \mathrm{H}$-uridine (aqueous solution, sp. act., $42 \mathrm{Ci} / \mathrm{mM}$ ) and $250 \mu \mathrm{Ci} / \mathrm{mL}$ of $5,6-3 \mathrm{H}$-cytidine (aqueous solution, sp. act. $30 \mathrm{Ci} / \mathrm{mM}$ ). Incubation time ranged from 24 to $48 \mathrm{~h}$. Chromosome preparations were fixed for $30 \mathrm{~min}$ in $2 \%$ paraformaldehyde and processed for autoradiography as previously described (PenradMobayed et al. 1986). Chromosomes were stained as described by (Gall et al. 1981) with Coomassie blue $(0.1 \%$ in $50 \%$ methanol, $10 \%$ acetic acid) for $10 \mathrm{~min}$.

Protein extraction, SDS polyacrylamide gel electrophoresis and Western blots

Oocytes were incubated in MBS containing $2 \%$ TCA $(w / v)$ for $20 \mathrm{~min}$ to precipitate proteins, washed with PBS and kept at $4{ }^{\circ} \mathrm{C}$ overnight before dissection. Airdried germinal vesicles were resuspended in Laemmli buffer and treated for electrophoresis. Cytoplasms from enucleated oocytes were homogenized in TrisEDTA buffer containing $0.1 \mathrm{mg} / \mathrm{mL}$ pancreatic ribonuclease $A$ and $10 \mathrm{mmol} / \mathrm{L}$ Pefabloc (Interchim, USA). The homogenate was centrifuged for $10 \mathrm{~min}$ at $10,000 \times g$. Proteins of the supernatant were precipitated overnight at $-20{ }^{\circ} \mathrm{C}$ The precipitate was recovered by $30 \mathrm{~min}$ centrifugation at $5,000 \times \mathrm{g}$ and treated for electrophoresis. The samples were denatured by heating in Laemmli buffer and separated in a 4-12\% NuPage gels (Invitrogen). After transfer, PVDF membranes were incubated overnight in PBS with $0.1 \%$ Tween 20 (PBST) and $5 \%$ fat-free dry milk at $4{ }^{\circ} \mathrm{C}$ and further incubated with either the primary rabbit polyclonal anti-Ro52 at 1:500 dilution or the monoclonal anti-alpha actin antibody (MP Biomedicals) at
1:10,000 dilution in PBS with $0.5 \%$ bovine serum albumin (BSA) for $1 \mathrm{~h}$. They were then washed in PBST, incubated with either an horseradish peroxidase (HRP)-conjugated goat anti-rabbit or an HRPconjugated rabbit anti-mouse (Jackson ImmunoResearch) diluted to $1: 10,000$ in PBS with $0.5 \%$ BSA for $1 \mathrm{~h}$ and washed in PBST. Detection was performed
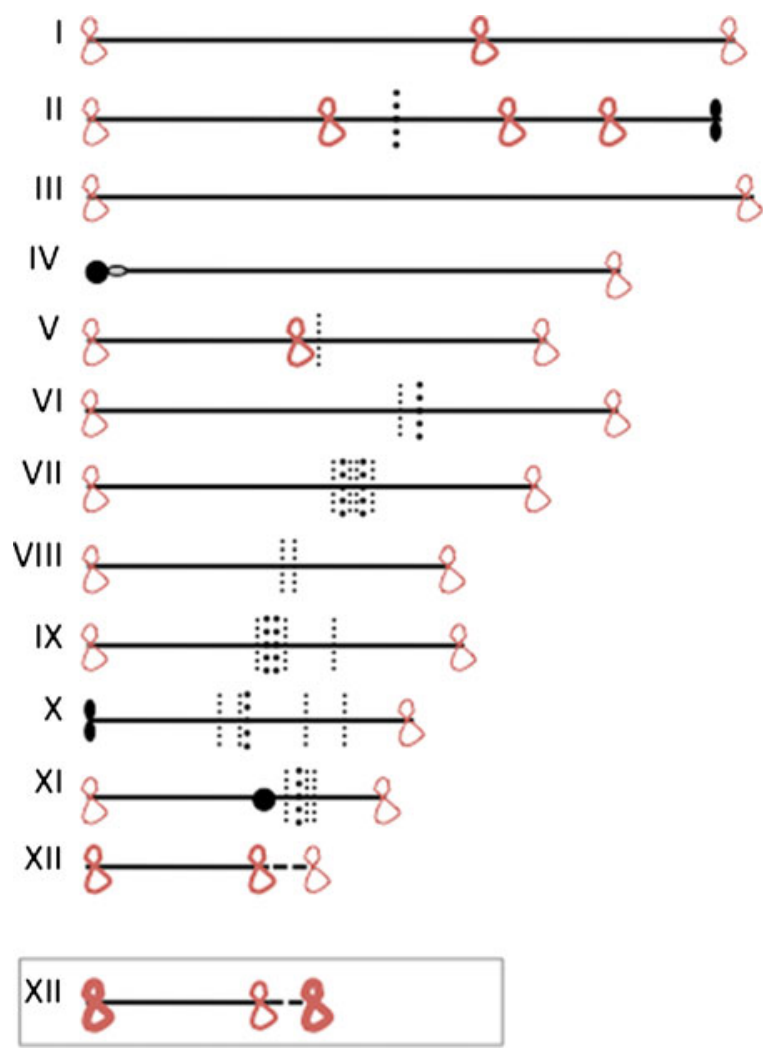

Fig. 1 Schematic map of the 12 LBCs of P. waltl. Chromosomes are oriented with their short arm to the right and numbered according to Lacroix et al. (1968). The map includes only the main identifying landmarks (black and grey symbols) reported by Lacroix et al. (1968) and the Ro52-labelled sites found in this study (red symbols). The right extremity of chromosome XII is often split, as indicated by the dashed line. The thin vertical dotted lines correspond to granular loops and the bold dotted lines to globular loops. Black symbols at the right end of chromosome II and left end of chromosome X indicate dense loops. Filled circles at the left end of chromosome IV and in the middle of chromosome XI indicate spheres. The grey oval symbol close to the sphere at the left end of chromosome IV corresponds to the M mass. Loops weakly labelled by the RO52 antibody are indicated by a thin red symbol and the strongly labelled ones by a thick red symbol. The position of the strongly labelled loops corresponds to that reported by Vishnyakova et al. 2004. After culture (box), only the left and right subterminal loops of chromosome XII underwent a prominent development and became intensely labelled (bold red symbols) 
using the ECL 'SuperSignal West Femto' (Thermo Scientific). Membranes were scanned with the LAS3000 imaging system (Fuji).

\section{Results}

Effects of in vitro culture on lampbrush chromosome structure

The mapping of $P$. waltl LBCs has been achieved thanks to their different lengths and the presence of conspicuous landmarks on 10 out of the 12 bivalents of the oocyte karyotype (Lacroix 1968; Fig. 1). LBCs were oriented according to their centromere location with the short arm to the right. Bivalent XII is the smallest of the $P$. waltl karyotype and lacks any regular identifying landmarks. However, several double bridges of the chromosome axis at the right extremity constitute a useful recognition feature (Fig. 2a). These split regions, which correspond to the separation of the two halves of the chromomere (Macgregor 2012), are fragile and often break during the LBC spreading procedure, resulting in the tearing off of the right end of the bivalent (Figs. 2b and 3a). Of note is that these double-axis regions are also observed in the smallest chromosome of the newts Triturus cristatus and Triturus marmoratus (for a review, see Callan 1986).

In full-grown stage VI oocytes, subterminal loops at the left and right extremities of bivalent XII exhibited a fine granular matrix with a distinguishable polarity (Fig. 3a-d). In oocytes incubated in vitro from 24 to $72 \mathrm{~h}$, these subterminal lampbrush loops remained well developed, but underwent prominent morphological modifications (Fig. 3e-h). The matrix of the left loops thickened and their axis coiled up in a pronounced spiral in the thickest regions (Fig. 3g). Changes affecting the right loops were spectacular. After $24 \mathrm{~h}$ of culture, they became covered with a thick matrix dotted with granules of progressively increasing size along their length (Figs. $3 \mathrm{~h}$ and $6 \mathrm{a}^{\prime}$ ). After $48 \mathrm{~h}$, these granules were fused in a continuous sheath around the loop axis (Fig. 6b'). This huge development of the left and right subterminal loops
Fig. 2 a Bivalent XII from full-grown (stage VI) oocytes of $P$. walt observed in phase contrast. This LBC is identifiable by its small size and the occurrence of double-axis regions at its right extremity (arrowhead). Arrows indicate left $(L E)$ and right $(R E)$ extremities of the bivalent. b Light microscope autoradiograph of part of bivalent XII isolated from an oocyte incubated for $48 \mathrm{~h}$ with tritiated cytidine and uridine. Two photographs had to be juxtaposed because bivalent XII is often stretched on nuclear spreads due to the frequent presence of double-axis regions (arrowheads) at the right extremity. c, d Enlarged images of the left $(S L L S)$ (c) and right $(S L R S)$ (d) subterminal loops shown in (b). Note that the conspicuous SLLs and SLRs together with some other loops of a standard type are strongly labelled. Bar represents $15 \mu \mathrm{m}$ in (a), $30 \mu \mathrm{m}$ in (b) and $10 \mu \mathrm{m}$ in (c) and (d)

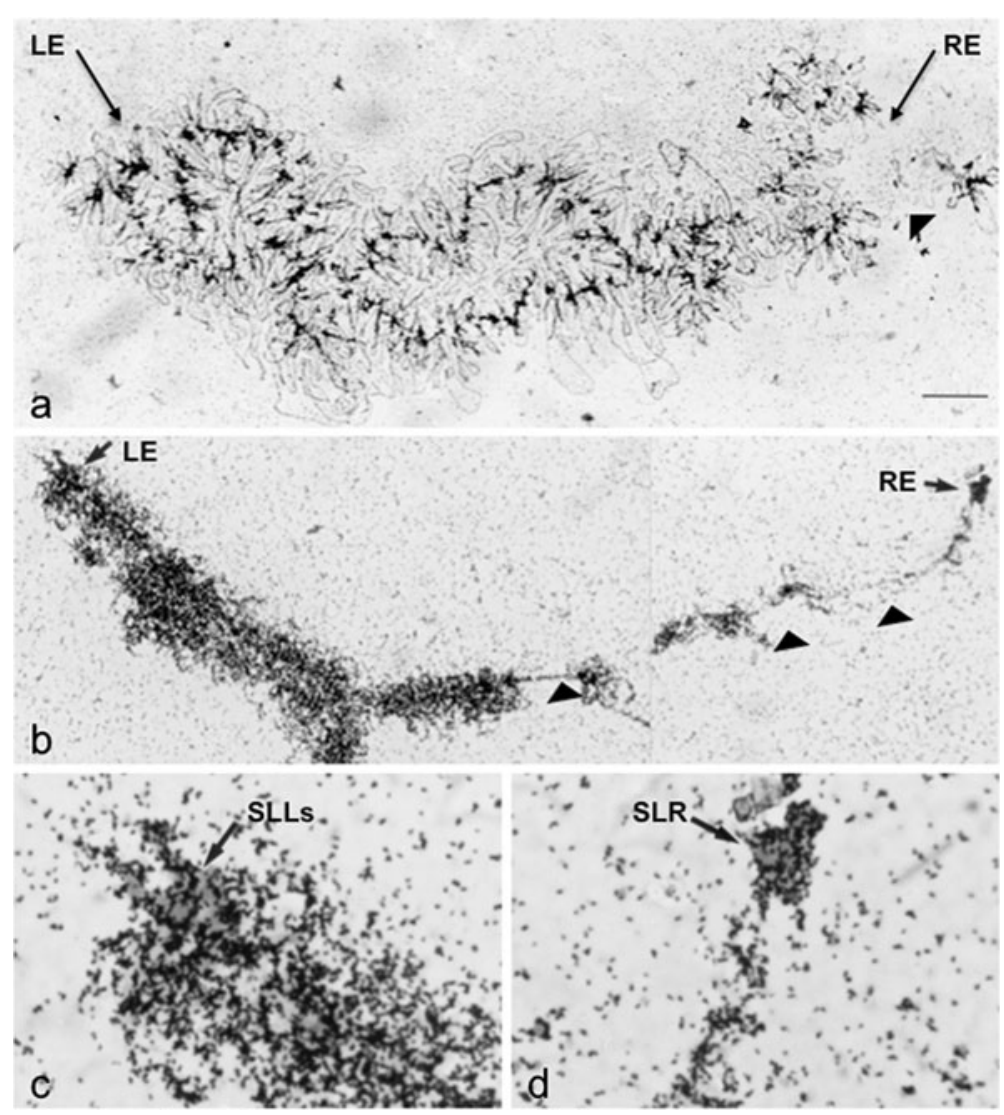


Fig. 3 Bivalent XII from full-grown oocytes of the same female before $(\mathbf{a}-\mathbf{d})$ and after $24 \mathrm{~h}(\mathbf{e}-\mathbf{h})$ of in vitro culture in the MBS solution. a, b General view of bivalent XII before culture: phase contrast (a) and Hoechst staining (b). Arrowheads point to the double bridges of one chromosome axis; the right extremity $(R E)$ of the other chromosome is broken (open arrowhead). c, d Enlarged images of the SLLs (c) at the left extremity $(L E)$ and SLRs (d) at the right extremity of the bivalent XII shown in (a). c Subterminal loops (SLLs) show an obvious polarity. Their thinnest part is close to the resolving limit of the light microscope. d Subterminal loops at the right extremity (SLRs). One SLR shows a light zigzag arrangement of its RNP matrix. e-h Bivalent XII after $24 \mathrm{~h}$ in vitro culture. e Phase contrast. f Hoechst staining. g, h Enlarged images of the SLLs (g) and SLRs (h) shown at the left and right extremities in (e). Note the important development of the RNP matrix of the SLRs. Bar represents $60 \mu \mathrm{m}$ in (a), (b), (e) and (f) and $15 \mu \mathrm{m}$ in (c), (d), (g) and (h)
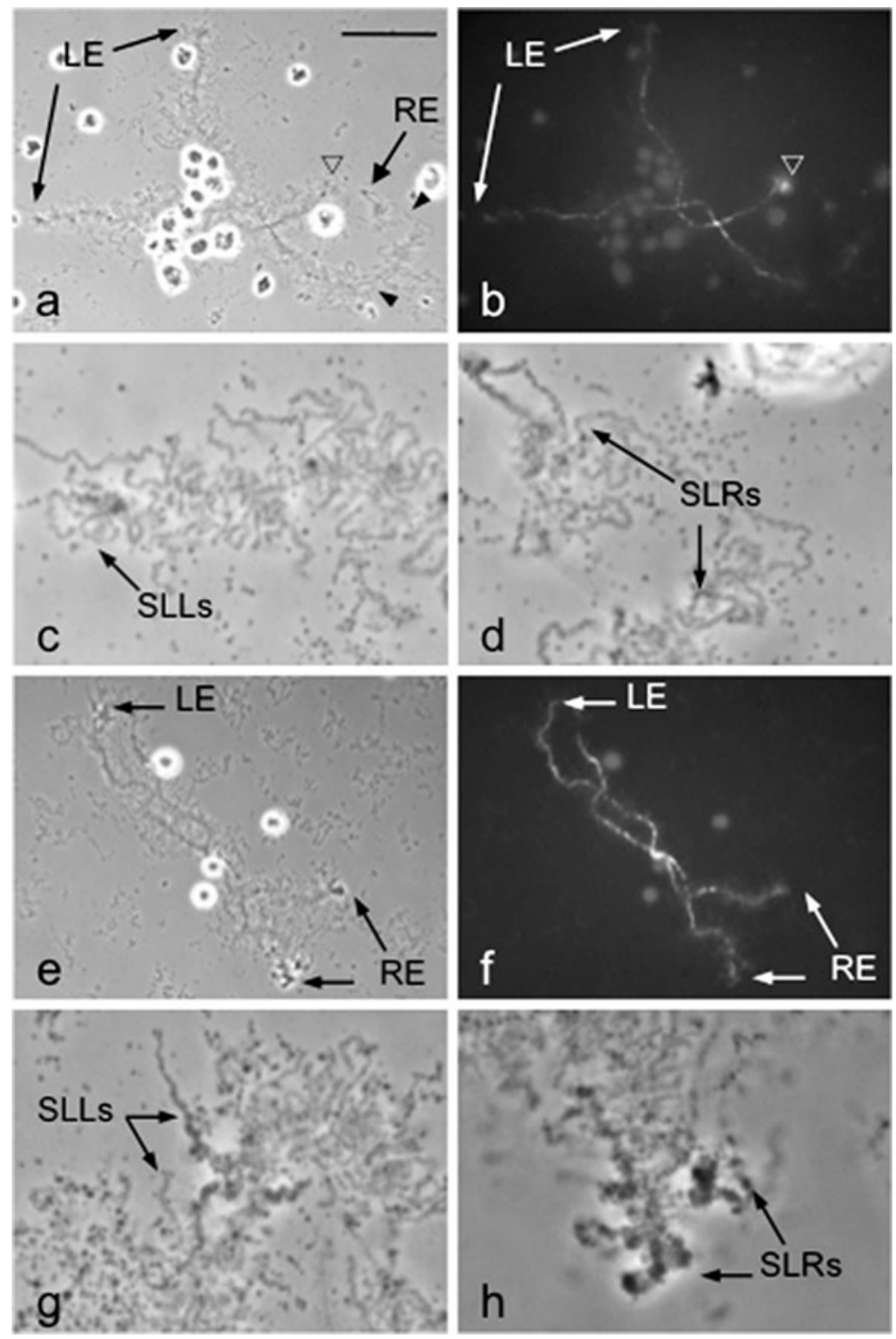

of bivalent XII was still observable after 10 days of culture. Similar morphological changes were recorded when the oocytes were cultured in the MBS solution or in the 199 medium with or without cycloheximide (data not shown). Active RNA transcription in the subterminal loops was not affected by the culture, as shown by the incorporation of RNA precursors into their matrix (Fig. 2b-d). In contrast, the subterminal loops of the other chromosomes did not undergo similar changes (Figs. $4 \mathrm{c}^{\prime}$ and $5 \mathrm{c}^{\prime}$ ). Other loops of the karyotype (Fig. $5 \mathrm{c}^{\prime}, \mathrm{d}^{\prime}$ ) became somewhat shortened and less extended, similar to what had been reported for LBCs from cultured full-grown oocytes of $T$. cristatus (Flannery and Hill 1988) and X. tropicalis (Penrad-Mobayed et al. 2010).

Immunolocalization of Ro52 on LBC spreads of $P$. waltl oocytes

Morphological changes occurring on one loop may be due to variations in the composition of proteins that form its RNP matrix. We investigated the possibility that the Ro52 protein might be one of them because Simon et al. (1998) and Vishnyakova et al. (2004) had reported previously the labelling of one loop near the right extremity of bivalent XII of $P$. walt using a 
Fig. 4 Immunostaining of Ro52 loci on LBCs from control oocyte before in vitro culture. Chromosomes were immunostained with the polyclonal Ro52 antibody/Alexa 488 (pseudocoloured in red) and counterstained with Hoechst (blue) to show the DNA axis (left panels). The corresponding phasecontrast images are shown on the right panels. Arrows point to the loop loci where the correspondence with their matching phasecontrast is obvious. a, $a^{\prime}, \mathbf{b}$, $b^{\prime}$ SLLs and SLRs of bivalent XII shown in Fig. 2c, d are labelled. Note that the SLLs and the small loop close to the SLRs (arrowhead) are more strongly labelled than the SLRs. c, $c^{\prime}$ Detailed region of another bivalent of the karyotype showing subterminal loops lightly labelled (arrow). d, $d$ ' Detailed region of bivalent $\mathrm{V}$ showing a pair of lateral loops strongly labelled (arrows). Bar represents $15 \mu \mathrm{m}$ in $(\mathbf{a}-\mathbf{d})$ and $\left(a^{\prime}-d^{\prime}\right)$
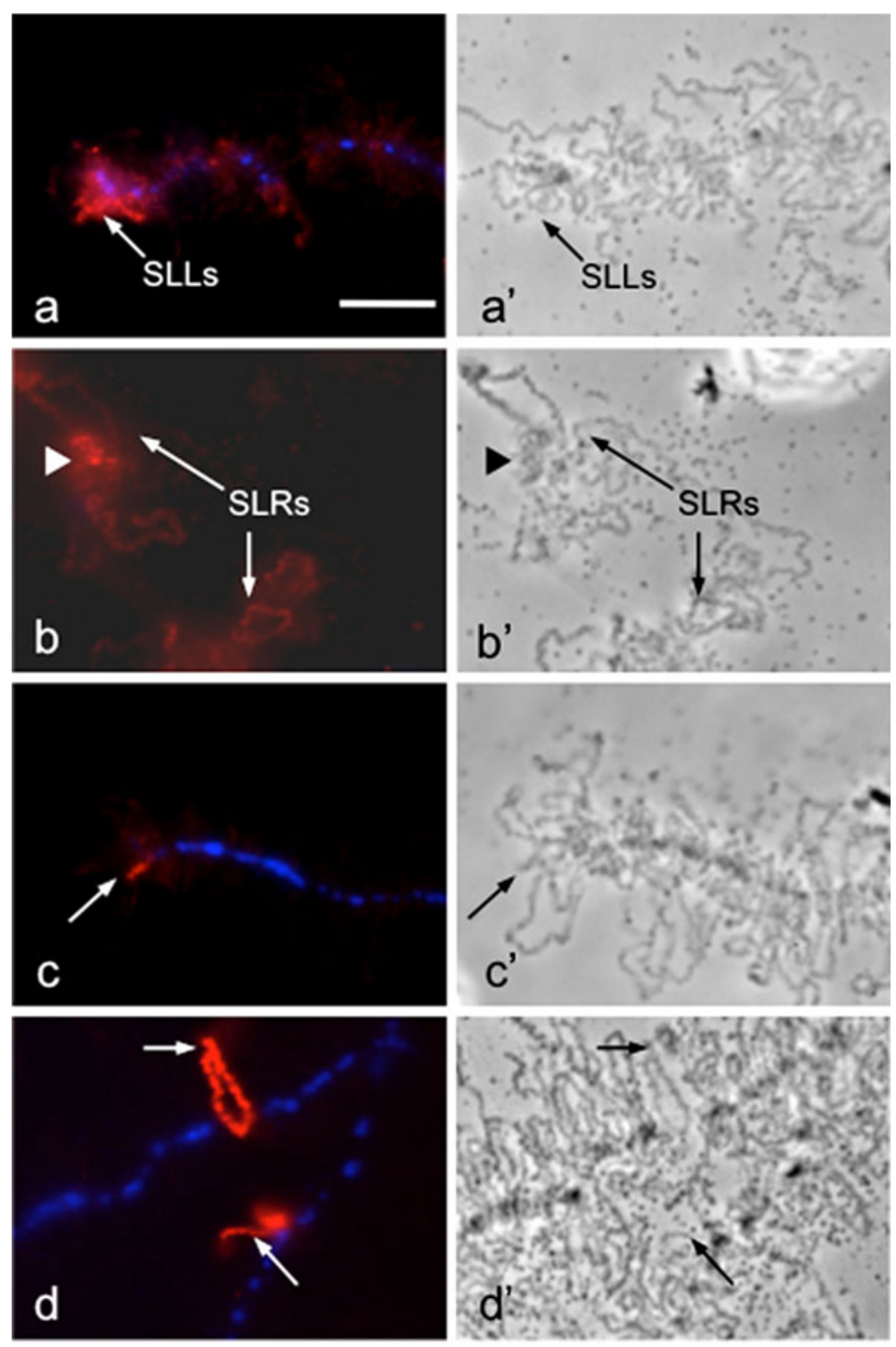

polyclonal anti-Ro52 antiserum. We first checked the specificity of this antiserum by immunoblotting using nuclear extracts of $P$. waltl oocytes. The antiserum reacted with one major band of the expected $52-\mathrm{kDa}$ molecular mass (Fig. 8a). When applied to LBCs from freshly isolated control oocytes, the anti-Ro52 antibody strongly labelled the left subterminal loops (Figs. 1 and $4 \mathrm{a}$ ) and one small loop close to the right subterminal loops, which were themselves lightly labelled (Figs. 1 and $4 \mathrm{~b}$ ). In addition, the antibody labelled strongly five loops on bivalent I, II and V and weakly subterminal loops on all these chromosomes (Figs. 1 and 4).
After $24 \mathrm{~h}$ of culture, both the left and right subterminal loops of bivalent XII became intensely labelled (Figs. 5a, b and 6a, b). In contrast, no changes in Ro52 staining of all the other chromosomal sites were observed during the same culture periods, as shown for the labelled loops of bivalent V (Fig. 5d) or the subterminal loops of the other chromosomes (Fig. 5c).

As a complementary means of identification of bivalent XII, when its structure was damaged in particular, we analysed the distribution of pol III loci using a polyclonal anti-RPC53 antiserum which had been shown to reveal chromosomespecific patterns of labelled loci on LBC axes of 
Fig 5 Immunostaining of Ro52 loci in LBCs from oocytes after $24 \mathrm{~h}$ of in vitro culture. Chromosomes were immunostained with the polyclonal Ro52 antibody/ Alexa 488 (pseudo-coloured in red) and counterstained with Hoechst (blue) to show the DNA axis (left panels). The corresponding phasecontrast images are shown on the right panels. a, $a^{\prime}, \mathbf{b}$, $b^{\prime}$ SLLs and SLRs of bivalent XII strongly labelled. c, $c^{\prime}$ Detailed region of another bivalent showing subterminal loops lightly labelled (arrows). d, $d^{\prime}$ Detailed region of bivalent $\mathrm{V}$ (similar to that shown in Fig 3d, d') exhibiting a pair of strongly labelled lateral loops (arrows). Bar represents $15 \mu \mathrm{m}$ in (a-d) and $\left(a^{\prime}-d^{\prime}\right)$
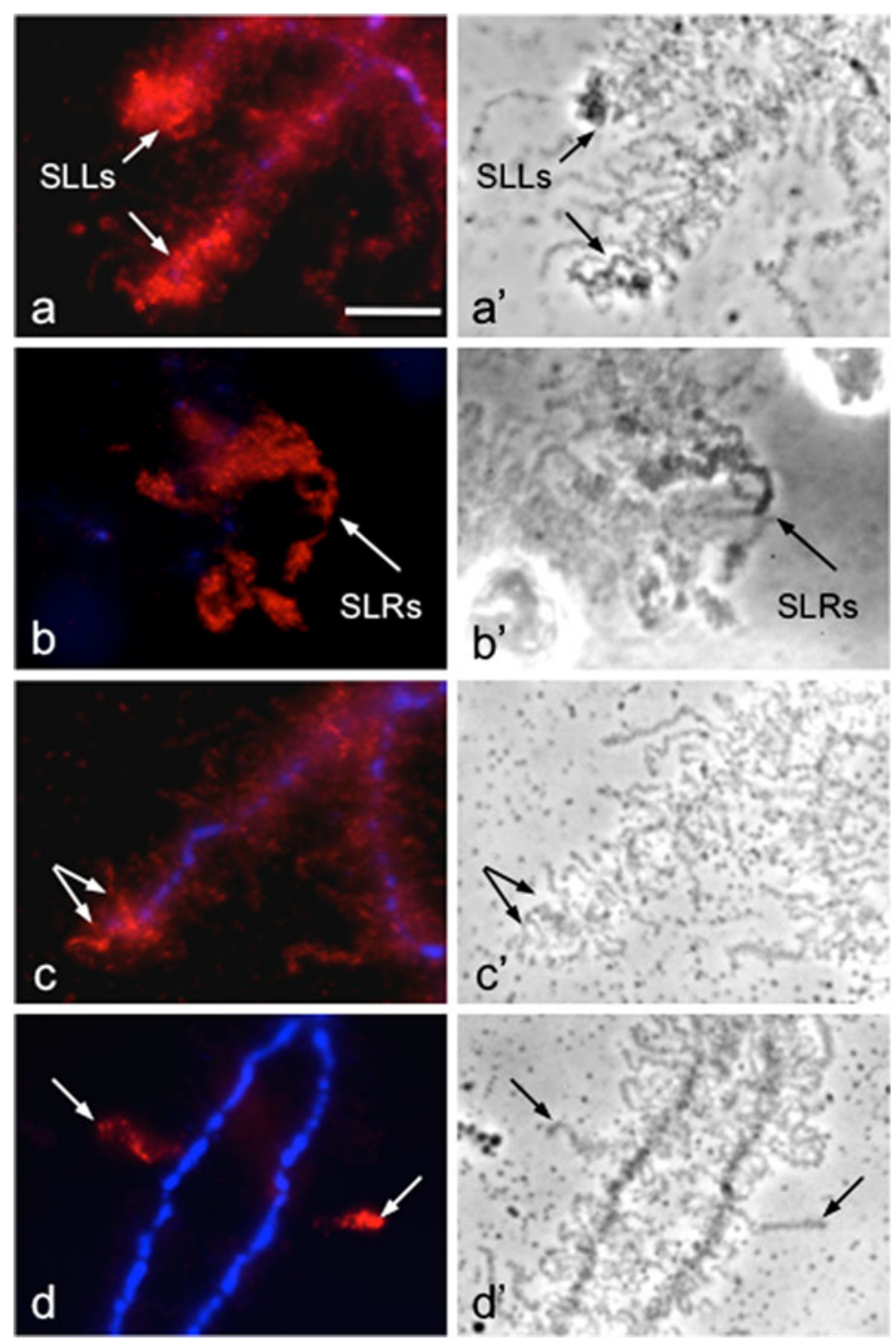

X. laevis (Murphy et al. 2002) and X. tropicalis (Penrad-Mobayed et al. 2009). Chromosomespecific patterns were also detected on $P$. walt LBC axes with this antibody (data not shown). In the case of bivalent XII, this pattern corresponded to two large staining patches on the left arm and two labelled spots on the right arm of the chromosome (Fig. 7). No staining of lateral loops was ever observed on any of the chromosomes of the karyotype. Surprisingly, after $24 \mathrm{~h}$ of culture, the left and right subterminal loops of bivalent XII became also strongly labelled with the anti-RPC53 antiserum, whilst staining of the four axial loci remained unchanged (Fig. 7). No changes in the staining pattern were observed either for the other chromosomes.

Changes in the nucleocytoplasmic distribution of Ro52 during in vitro culture

The nucleocytoplasmic distribution of the Ro52 protein in the course of a 3-day culture was compared to that of freshly isolated controls. In the control oocyte, a Ro52 immunoreacting band was observed in both the nuclear and cytoplasmic extracts. During the in vitro culture, the intensity of this band increased in 
Fig. 6 Immunostaining of Ro52 loci on bivalent XII after $24 \mathrm{~h}\left(\mathbf{a}, a^{\prime}\right)$ or $48 \mathrm{~h}(\mathbf{b}, b$ ') of in vitro culture in the 199 medium. Chromosomes were immunostained with the polyclonal Ro52 antibody/Texas Red-streptavidin (red) and counterstained with DAPI (blue) to show the DNA axis. The SLLS and SLRs $(\mathbf{a}, \mathbf{b})$ are strongly labelled. Note the presence of large granules in the RNP matrix of the SLRs after $24 \mathrm{~h}$ of culture $\left(a^{\prime}\right)$ and the huge development of the SLRs after $48 \mathrm{~h}$ of culture ( $b$ '). Note that chromosome axes shortened after in vitro culture. Bar represents $25 \mu \mathrm{m}$ in $\mathbf{a}, a^{\prime}$ and $\mathbf{b}, b^{\prime}$
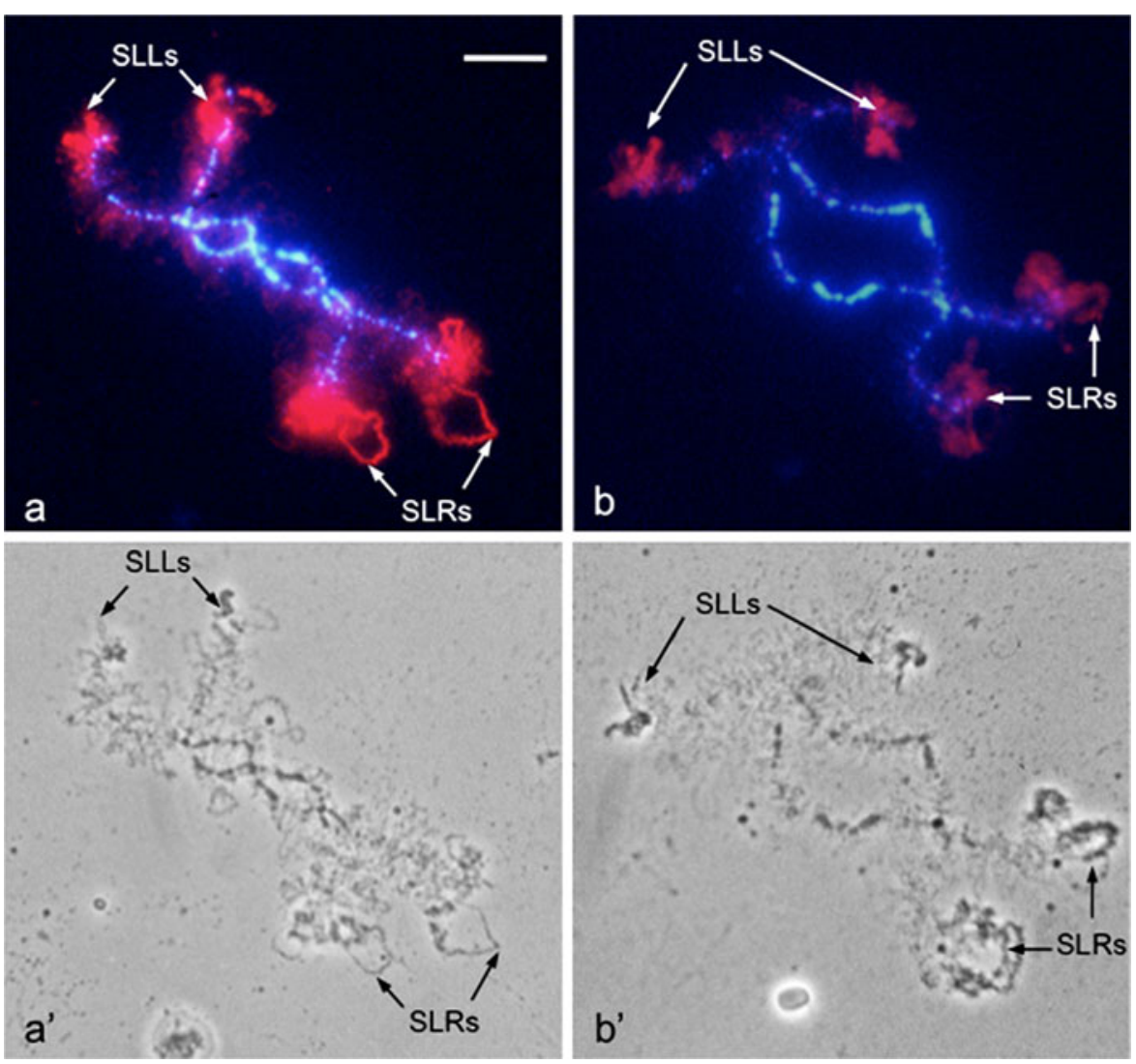

the nuclear extract whereas it decreased markedly in the cytoplasmic extract (Fig. 8b).

\section{Discussion}

Prolonged in vitro culture of full-grown $P$. walt oocytes led to a huge development of the RNP matrix of the subterminal loops of bivalent XII, the right ones in particular. The appearance of these atypical structures that we propose to refer to as 'chaussons' (slippers) is likely due to an accumulation of proteins that interact with the RNP transcripts of these loops. Among these proteins is a human Ro52-related protein whose nuclear level increases in parallel with the increase in the staining intensity of the RNP matrix of the subterminal loops of bivalent XII during the in vitro culture.

The question arises whether similar culture-induced modifications could be observed in amphibians other than P. waltl. Gurdon et al. (1971) initiated the use of in vitro-cultured amphibian oocytes as an experimental system. They demonstrated that oocytes cultured in a simple saline solution could translate any injected mRNA over a long period with a high efficiency and no species specificity. Since then, in vitro culture of injected oocytes for 1-3 days has been used extensively to analyse with LBCs as readout the effect on mRNA translation, chromatin condensation and nucleo-cytoplasmic trafficking of a variety of molecules, be they oligonucleotides, RNAs, plasmid DNAs or antibodies (for a review, see Morgan 2002). The vast majority of these studies has been carried out with $X$. laevis oocytes whose LBCs display lateral loops with a smaller size compared to that of the newt LBCs. This may be the reason why no culture-induced modification of the morphology of Xenopus LBC lateral loops has been reported to date. To our knowledge, however, no detailed study of such modifications has been reported either in newt species in which LBCs have been mapped.

Similarly to Vishnyakova et al. (2004), we have observed that less than ten loops distributed over four bivalents including bivalent XII, some of them of a large size, were stained with the anti-Ro52 antibody in $P$. walt oocytes before culture. We have detected 
Fig. 7 Immunodetection of pol III sites on bivalent XII after $24 \mathrm{~h}$ of in vitro culture. Fluorescent $(\mathbf{a}, \mathbf{b})$ and corresponding phasecontrast micrographs (c) of a nuclear spread immunostained with the polyclonal anti-RPC53 antiserum ( $\alpha$ RPC53) coupled with Alexa 488 (pseudo-coloured in red) and counterstained with Hoechst (blue) to show the DNA axis. Bivalent XII can be easily identified by the strong staining of two larges patches on the left arm and two granules at the right arm (a) that overlap with those visible in (b) (white arrowheads). After in vitro culture, the antiserum stained also the SLLs and SLRs. Bar represents $20 \mu \mathrm{m}$ in $\mathbf{a}-\mathbf{c}$
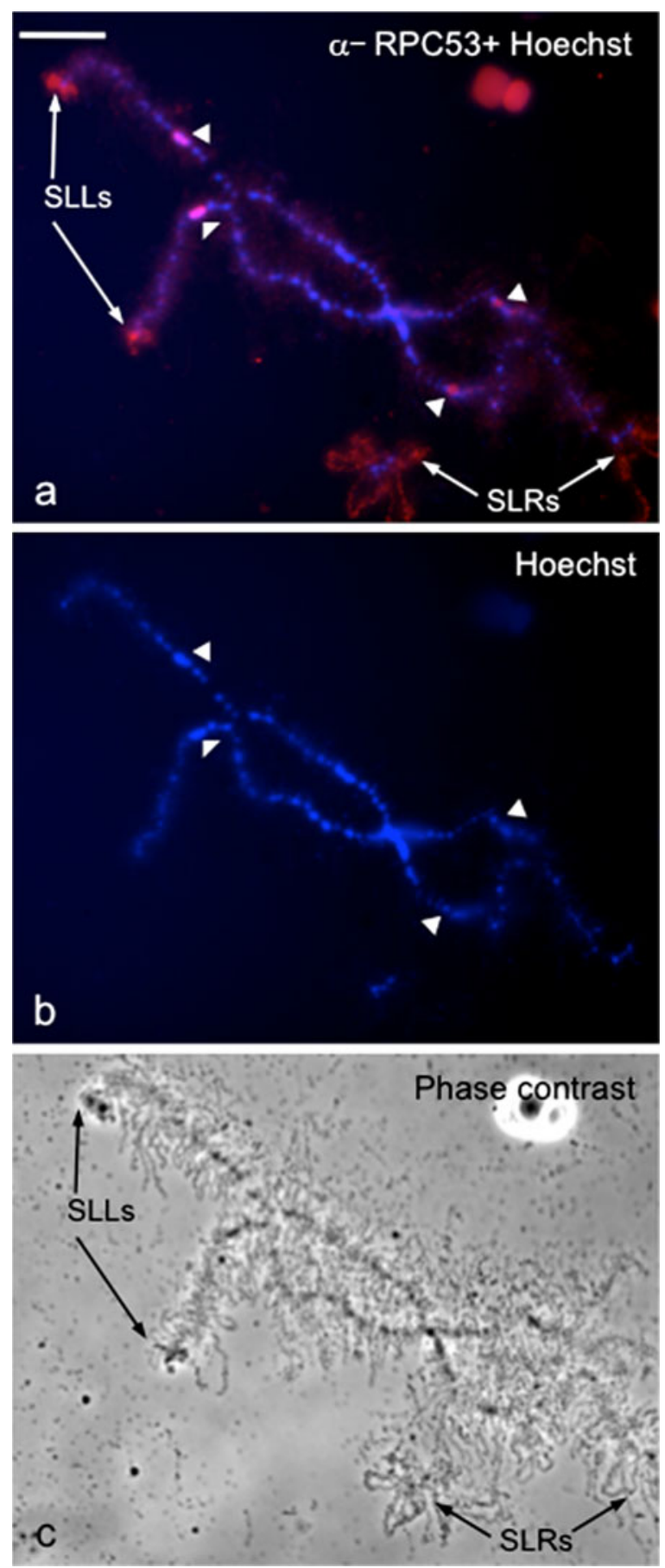

subterminal loops of bivalent XII underwent a modification into a 'chausson' structure upon in vitro culture. This implies that the RNP matrix of these loops may differ from that of other Ro52-specific loops. As mentioned above, loops comprised a DNA axis and an RNP matrix composed of RNA and proteins either additional labelled loci not described by Vishnyakova et al. (2004), such as the subterminal loops at the left extremity of bivalent XII and the subterminal loops at the ends of other bivalents (Fig. 1). All these loops exhibited a morphologically similar RNP matrix in phase microscopy. It is remarkable that only the 


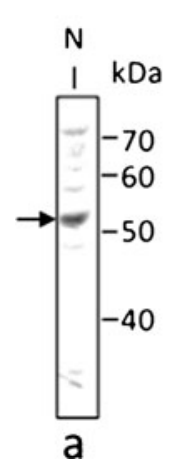

Fig. 8 Nucleocytoplasmic distribution of the Ro52 protein. Western blot of nuclear and cytoplasm extracts from control and in vitro-incubated oocytes from 24 to $72 \mathrm{~h}$ using the polyclonal anti-Ro52 antibody. Anti alpha-actine was used as a control of the input amount. Each slot corresponds to $30 \mathrm{GVs}$ or three cytoplasms. a Control of the specificity of the polyclonal anti-Ro52 antibody. Note the major 52-kDa band

common to all transcribed loops or specific of a subset of them. Proteins in the loops can bind to DNA or nascent RNAs either directly or indirectly through protein-protein interactions. This may be the case for the Ro52 protein. Ro52, also referred to as $52-\mathrm{kDa}$ Ro/ SSA in clinical practice, is one of the major autoantigens targeted in different autoimmune diseases such the Sjögren's syndrome (SS) and systemic lupus erythematosus (SLE). It is also named TRIM21 because it belongs to the tripartite motif (TRIM) family of proteins that are characterized by a RING finger domain, a b-box motif and a coiled-coil domain containing a leucine zipper motif. In Ro52, the coiled-coil domain, which is important for cytoplasmic localisation of the protein, is followed by a B30.2 (PRYSPRY) motif in the C-terminal end that is essential for its nuclear translocation (for a review, see Oke and Wahren-Herlenius 2012). Ro52 has been demonstrated to function as a transcription factor (Frank 1999; Wang et al. 2001), and more recently, it has been shown to possess an E3 ligase activity and act in the process of ubiquitinylation (Wada and Kamitani 2006; Espinosa et al. 2008).

We have observed that Ro52, initially detected at similar levels in the cytoplasm and GV of the $P$. waltl oocyte, accumulated in the GV during in vitro culture. This nuclear translocation could explain the appearance of a strong immunostaining of the large granules accumulated in the RNP matrix of the 'chaussons'. Simple diffusion is probably not involved in this translocation process because Simons et al. (1994) have shown that the human Ro52 protein microinjected into
$X$. laevis oocytes is translocated into the nucleus via an active transport mechanism. A parallel can be drawn between the nuclear translocation of Ro52 during the in vitro culture of the $P$. walt oocyte and its similar translocation reported in mammals where it has been shown to be expressed in most tissues and cells with either a predominantly cytoplasmic or a nuclear location according to the cell type (for review, see Oke and Wahren-Herlenius 2012). Ro52 has also been demonstrated to translocate from the cytoplasm to the cell surface or into the nucleus in apoptotic or stressed cells, as is the case in HeLa cells exposed to extrinsic factors such as NO (Espinosa et al. 2008; for review, see Oke and Wahren-Herlenius 2012).

On the basis of our results, we propose that the dissociation of the amphibian oocyte from the environing maternal tissues and its in vitro culture induces a stress to the oocyte, which triggers the nuclear translocation of Ro52 and its accumulation in association with other proteins such as pol III and Ro RNP particles at the level of specific transcripts where they perform a function related to the metabolism or the degradation of nuclear RNAs. A convergent set of data support this hypothesis. Firstly, the Ro52 protein has been suggested to be associated directly or indirectly with the Ro ribonucleoprotein particles (Ro RNPs; see Fabini et al. 2000) which comprised the Ro60 protein, small YRNAs and the La protein (Wolin and Steitz 1984; Ben-Chetrit et al. 1988). The La protein has been shown to function as a transcription termination factor of pol III (Gottlieb and Steitz 1989) and the 
small YRNAs are transcribed by pol III. Ro60, another major autoantigen targeted in the autoimmune diseases SS and SLE, is a ring-shaped RNA-binding protein. It has been proposed to be involved in the degradation of misfolded small RNAs and to play an important role in animal cells for adapting RNA metabolism in response to environmental stress (Stein et al. 2005; for a review, see Sim and Wolin 2011). It is noteworthy that after either UV irradiation or oxidative stress, Ro60 undergoes a translocation from the cytoplasm to the nucleus similar to that of Ro52 (Chen et al. 2003; Sim et al. 2009). Secondly, as mentioned above, Ro52 has an E3 ubiquitin ligase activity. Although ubiquitin ligases are best recognized for their role in protein degradation, recent data point to a novel role in the degradation of nucleic acids. This is the case for MEX-3C (Cano et al. 2012) and Roquin (Vinuesa et al. 2005) whose mutation may result in a lupus-like pathology in the mouse. Contrary to MEX3C and Roquin, Ro52 does not have an RNA-binding domain, but it may play a cofactor role in the degradation of RNAs. Thirdly, we think that the detection of pol III at the level of the subterminal loops of bivalent XII after culture is indicative of its accumulation on these loops and not of its involvement in their transcription. Active sites of pol III transcription corresponding to 5S, tRNA, spliceosomal U snRNAs and other small noncoding RNAs genes are located at the level of lateral loops whose RNP matrix is not detectable in phasecontrast microscopy (Murphy et al. 2002). By comparison, the RNP matrix of the subterminal loops of bivalent XII was clearly visible before culture, and the accumulation of Ro52 and Pol III may thus result from the presence on these loops of transcripts of a peculiar structure, allowing these proteins to be drawn up and accumulated at these sites.

\section{Concluding remarks}

As discussed above, we favour the idea that the accumulation of Ro 52 and pol III proteins we have observed in cultured $P$. waltl oocytes reveals the storage at these sites of large quantities of the components of a nuclear machinery including Ro RNPs, which provides a quality control of RNA synthesis and maturation in response to cellular stress. It is noteworthy that the association of Ro52 with Ro RNPs is still an open question which had not been resolved by direct biochemical purification approaches (Boire et al. 1995; Fabini et al. 2000). We think that LBCs, and the newt LBCs in particular, provide an invaluable biological system for settling this issue of a general importance for unravelling the relationships and functional role of the Ro proteins and RNPs. New cellular imaging methods have been developed for the study of LBCs, such as the visualisation of LBCs in oil-isolated GVs under in vivo-like conditions (Patel et al. 2008) or the analysis of the distribution of proteins on specific loops by superresolution imaging (Kaufmann et al. 2012). These should provide powerful tools for studying the localisation and dynamics of the different protein partners of the Ro RNPs directly at the level of the loop matrix.

Finally, it can be stressed that the vast majority of studies concerning the biological properties of Ro52 have been carried out on somatic cells so far. In vitro culture of mammalian oocytes is extensively used in ART in humans and animals. Our results raise the question whether the nuclear accumulation of Ro52 occurs also in these oocytes in the course of in vitro fertilization procedures and of what might be the consequences on subsequent foetal development.

Acknowledgments We are grateful to Sylviane Muller (I.B.M.C Strasbourg) for the gift of the anti Ro52 antibody and to Robert Roeder for the anti-RPC53 antibody. We thank Nicole Moreau, Ouassila Habi and Samira Asfoura for their contributions at the start of this study and Reiner Veitia for support and discussions.

\section{References}

Angelier N, Bonnanfant-Jaïs ML, Herberts C, Lautredou N, Moreau N, N'Da E, Penrad-Mobayed M, RodriguezMartin ML, Sourrouille P (1990) Chromosomes of amphibian oocytes as a model for gene expression: significance of lampbrush loops. Int J Dev Biol 34:69-80

Boire G, Gendron M, Monast N, Bastin B, Ménard HA (1995) Purification of antigenically intact Ro ribonucleoproteins; biochemical and immunological evidence that the $52-\mathrm{kD}$ protein is not a Ro protein. Clin Exp Immunol 100:489-498

Ben-Chetrit E, Chan EK, Sullivan KF, Tan EM (1988) A 52-kD protein is a novel component of the SS-A/Ro antigenic particle. J Exp Med 167:1560-1571

Bonnanfant-Jaïs ML, Mentré P (1983) Study of oogenesis in the different stages of oocyte development. J Submicrosc Cytol 15:453-478

Callan HG (1986) Lampbrush chromosomes. Springer, Berlin

Callan HG, Gall JG, Berg CA (1987) The lampbrush chromosomes of Xenopus laevis: preparation, identification and distribution of 5S DNA sequences. Chromosoma 95:236-250 
Cano F, Bye H, Duncan LM, Buchet-Poyau K, Billaud M, Wills MR, Lehner PJ (2012) The RNA-binding E3 ubiquitin ligase MEX-3C links ubiquitination with MHC-I mRNA degradation. EMBO J 31:3596-3606

Chen X, Smith JD, Shi H, Yang DD, Flavell RA, Wolin SL (2003) The Ro autoantigen binds misfolded U2 small nuclear RNAs and assists mammalian cell survival irradiation. Curr Biol 13:2206-2211

Espinosa A, Oke V, Elfving A, Nyberg F, Covacu R, WahrenHerlerius M (2008) The autoantigen Ro52 is an E3 ligase resident in the cytoplasm but enters the nucleus upon cellular exposure to nitric oxide. Exp Cell Res 314:3605-3613

Fabini G, Rutjes SA, Zimmermann C, Pruijn GJ, Steiner G (2000) Analysis of the molecular composition of Ro ribonucleoprotein complexes. Identification of novel Y RNAbinding proteins. Eur J Biochem 267:2778-2789

Flannery AV, Hill RS (1988) The effect of heat shock on the morphology of amphibian lampbrush chromosomes. Exp Cell Res 177:9-18

Frank MB (1999) Characterization of DNA binding properties and sequence specificity of the human $52 \mathrm{kDa}$ Ro/SS-A (Ro52) zinc finger protein. Biochem Biophys Res Commun 259:665-670

Gall JG, Stephenson EC, Erba HP, Diaz MO, Barsacchi-Pilone G (1981) Histones genes are located at the sphere loci of newt lampbrush chromosomes. Chromosoma 84:159-171

Gall JG, Wu Z, Murphy C, Gao H (2004) Structure in the amphibian germinal vesicle. Exp Cell Res 296:28-34

Gottlieb E, Steitz JA (1989) The RNA binding protein la influences both accuracy and the efficiency of RNA polymerase III transcription in vitro. EMBO J 8:841-850

Gurdon JB (1977) Methods for nuclear transplantation in amphibia. Methods Cell Biol 16:125-139

Gurdon JB, Lane CD, Woodland HR, Marbaix G (1971) Use of frog eggs and oocytes for the study of messenger RNA and its translation in living cells. Nature 233:177-182

Halley-Stott RP, Pasque V, Astrand C, Miyamoto K, Simeoni I, Jullien J, Gurdon JB (2010) Mammalian nuclear transplantation to germinal vesicle stage Xenopus oocytes - a method for quantitative transcriptional reprogramming. Methods 51:56-65

Kaufmann R, Cremer C, Gall JG (2012) Superresolution imaging of transcription units on newt lampbrush chromosomes. Chromosome Res. doi:10.1007/s10577-012-9306-Z

Lacroix JC (1968) Etude descriptive des chromosomes en écouvillon dans le genre pleurodeles (Amphibien, Urodèle). Ann Embryol Morphogen 1:179-202

Macgregor HC (2012) Chromomeres revisited. Chromosome Res. doi:10.1007/s10577-012-9310-3

Morgan GT (2002) Lampbrush chromosomes and associated bodies: new insights into principles of nuclear structure and function. Chromosome Res 10:177-200

Murphy C, Wang Z, Roeder RG, Gall JG (2002) RNA polymerase III in Cajal bodies and lampbrush chromosomes of the Xenopus oocyte nucleus. Mol Biol Cell 13:3466-3476

Oke V, Wahren-Herlenius M (2012) The immunobiology of Ro52 (TRIM21) in autoimmunity: a critical review. J Autoimmun 39:77-82

Patel S, Novikova N, Beenders B, Austin C, Bellini M (2008) Live images of RNA polymerase II transcription units. Chromosome Res 16:223-232
Penrad-Mobayed M, Bonnanfant-Jaïs ML, N'Da E, Angelier N (1986) Evidence for a particular mode of transcription in globular loops of lampbrush chromosomes of the newt Pleurodeles waltlii. Chromosoma 94:319-328

Penrad-Mobayed M, El Jamil A, Kanhoush R, Perrin C (2009) Working map of the lampbrush chromosomes of Xenopus tropicalis: a new tool for cytogenetic analyses. Dev Dyn 238:1492-1501

Penrad-Mobayed M, Kanhoush R, Perrin C (2010) Tips and tricks for preparing lampbrush chromosome spreads from Xenopus tropicalis oocytes. Methods 51:37-44

Ricchiuti V, Pruijn GJ, Thijssen JP, van Venrooij WJ, Muller S (1997) Accessibility of epitopes on the 52-kD Ro/SSA protein (Ro52) and on the RoRNP associated Ro52 protein as determined by anti-peptide antibodies. J Autoimmun 10:181-191

Sim S, Wolin SL (2011) Emerging roles for the Ro $60 \mathrm{kDa}$ autoantigen in noncoding RNA metabolism. WIREs RNA 2:686-699

Sim S, Weinberg DE, Fuchs G, Choi K, Chung J, Wolin SL (2009) The subcellular distribution of an RNA quality control protein, the Ro autoantigen, is regulated by noncoding Y RNA binding. Mol Biol Cell 20:1555-1564

Simons FHM, Pruijn GJM, van Venrooij WJ (1994) Analysis of the intracellular localization and assembly of Ro ribonucleoprotein particles by microinjection into Xenopus laevis oocytes. J Cell Bio 1 125:981-988

Simon F, Vichniakova N, Pyne C, Lacroix J-C (1998) Les chromosomes en écouvillon d'amphibiens. In: Popescu P, Hayes H, Dutrillaux B (eds) Techniques de cytogénétique animale. INRA, Paris, pp 119-151

Sommerville J (2010) Using oocyte nuclei for studies on chromatin structure and gene expression. Methods 51:157-164

Stein AJ, Fuchs G, Fu C, Wolin SL, Reinisch KM (2005) Structural insights into RNA quality control: the Ro autoantigen binds misfolded RNAs via its central cavity. Cell 121:529-539

Vinuesa CG, Cook MC, Angelucci C, Athanasopoulos V, Rui L, Hill KM, Yu D, Domaschenz H, Whittle B, Lambe T, Roberts IS, Copley RR, Bell JI, Cornall RJ, Goodnow CC (2005) A RING-type ubiquitin ligase family member required to repress follicular helper $\mathrm{T}$ cells and autoimmunity. Nature 435:452-458

Vishnyakova NM, Lacroix JC, Rodionov AV (2004) Cytogenetic maps of lampbrush chromosomes of newts of the genus Pleurodeles: an algorithm of lampbrush chromosome identification in Pleurodeles waltl by immunocytochemical marker-loop staining with polyclonal anti-Ro52 antisera. Genetika 40:614-623

Wada K, Kamitani T (2006) Autoantigen Ro52 is an E3 ubiquitin ligase. Biochem Biophys Res Commun 339:415-421

Wang D, Buyon JP, Yang Z, Di Donato F, Miranda-Carus ME, Chan EK (2001) Leucine zipper domain of $52 \mathrm{kDa}$ SS-A/Ro promotes protein dimer formation and inhibits in vitro transcription activity. Biochim Biophys Acta 1568:155-161

Wolin SL, Steitz JA (1984) The Ro small cytoplasmic ribonucleoproteins: identification of the antigenic protein and its binding site on the Ro RNAs. Proc Natl Acad Sci U S A 81:1996-2000 